\title{
PIV Measurements and Computational Study of a 5-Inch Ducted Fan for V/STOL UAV Applications
}

\author{
Ali Akturk $^{1}$, Akamol Shavalikul $^{2}$ and Cengiz Camci $^{3}$ \\ Vertical Lift Research Center of Excellence (VLRCOE) \\ Turbomachinery Aero-Heat Transfer Laboratory, Department of Aerospace Engineering, \\ The Pennsylvania State University, University Park, PA 16802
}

Ducted fan vertical/short take-off and landing (V/STOL) uninhabited aerial vehicles (UAV) are popular because of their capacity of offering a higher static thrust/power ratio for a given diameter than open propellers. They are also known as camera/antenna carrying or sensor positioning devices. Because of their complicated missions, they need to be capable of flight in a broad range of atmospheric conditions. In forward flight, the performance of these vehicles is poor because of the distorted inlet flow. The present experimental study uses a planar particle image velocimeter (PIV) system to investigate the near duct aerodynamic performance in hover and forward flight condition. High resolution PIV measurements provide reliable aerodynamic measurements forming a validation basis for further analytical and computational design studies. A radial equilibrium based fan aerodynamic model in combination with angular momentum conservation principle and energy equation is effectively integrated into a three-dimensional RANS based computational system. PIV measurements and computational predictions of mean flow near the fan inlet plane are in very good agreement at hover conditions. The aerodynamic modifications due to fan inlet flow distortions in forward flight regime are clearly displayed in PIV results.

\section{Nomenclature}

$\begin{array}{ll}\beta_{1}, \beta_{2} & =\text { Blade inlet, exit angle measured from axial direction } \\ c_{1}, c_{2} & =\text { Rotor inlet, exit absolute velocity } \\ c_{\theta} & =\text { Tangential (swirl) velocity component } \\ c_{x} & =\text { Axial velocity } \\ p & =\text { Static Pressure } \\ P_{o} & =\text { Total Pressure } \\ \Omega & =\text { Rotational Speed (radian/sec) } \\ r & =\text { radial distance measured from origin } \\ w_{1}, w_{2} & =\text { Rotor inlet,exit relative velocity (also } W \text { ) } \\ \rho & =\text { Density }\end{array}$

\section{Introduction}

$\mathrm{D}$ UCTED fans that are popular choices in vertical/short take-off and landing (V/STOL) uninhabited aerial vehicles (UAV) offer a higher static thrust/power ratio for a given diameter than open propellers. That is the result of diffusion of the propeller jet stream. They also provide an impact protection for the blades and improve personnel safety due to its enclosed fan structure as well as the lower noise level in the plane of the fan blade

\footnotetext{
1,2 Graduate research assistants

3 Professor, Dept. of Aerospace Engineering, 223 Hammond Building, University Park, PA 16802 cxc11@psu.edu 1

American Institute of Aeronautics and Astronautics
} 
rotating. Currently, there are several ducted fan V/STOL UAVs available in the market. Recent examples of V/STOL UAV systems are shown in Figure 1.

The viscous flow characteristics of the ducted fan are very complex. These vehicles need to be capable of flight in a broad range of atmospheric conditions, including the complex turbulent flow fields around buildings and trees. When a V/STOL ducted fan is in horizontal flight, because of the relative inlet flow dominantly parallel to its inlet plane, problems related to flow separation at the leading edge duct lip are encountered. The inlet flow separation leads to problems within the duct and may well result in a high pitch-up moment as the forward speed is increased. Therefore measuring and predicting the mean flow characteristics of ducted fans is crucial to understand the problems related to reliable and controllable horizontal flights. Numerous studies have been undertaken in order to quantify the flow field properties around ducted fans. The operation of an axial flow fan with strong inlet flow distortion severely affect the performance of the rotor especially near the tip region of the blades.
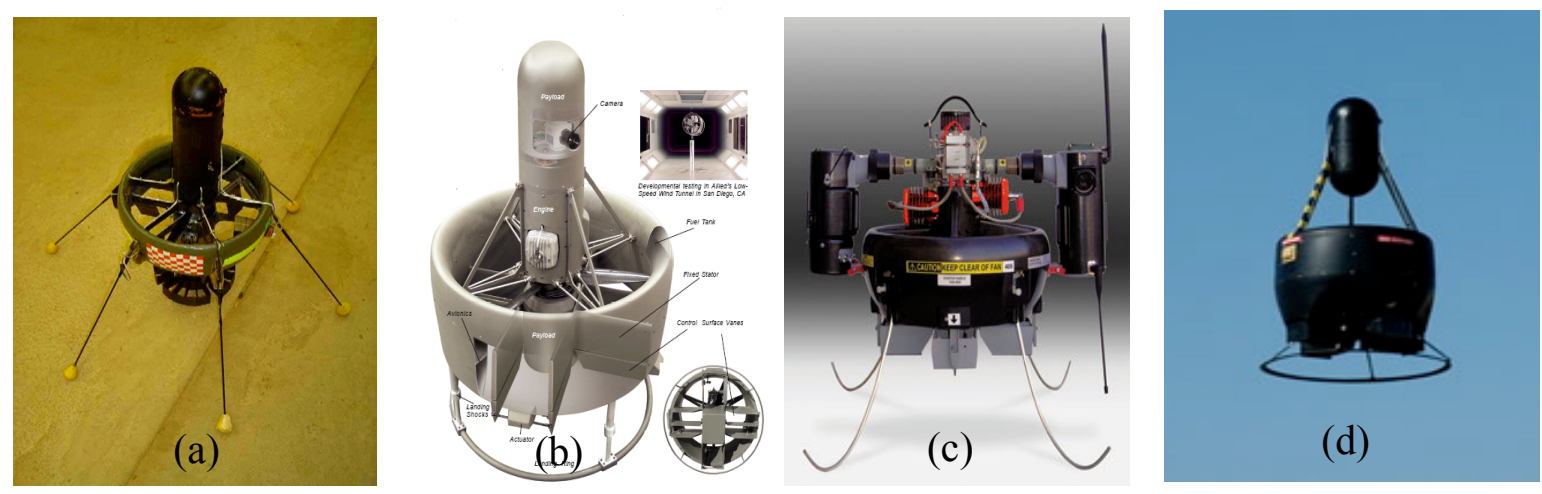

Figure 1. Examples of VSTOL/UAVs (a) Mass Helispy (b) I-STAR (c) Honeywell MAV (d) BAE IAV2

Experimental investigation has been the major approach to study the mean flow characteristics of the ducted fan. Abrego and Bulaga ${ }^{1}$ performed wind tunnel tests to determine the performance characteristics of ducted fans for axial and forward flight conditions. Their study resulted in showing important effect of exit vane flap deflection and flap chord length on providing side force. Martin and Tung ${ }^{2}$ tested a ducted fan V/STOL UAV with a 10-inch diameter fan rotor. They measured aerodynamic loads on the vehicle for different angle of attacks in hover and different crosswind velocities. They also included hot-wire velocity surveys at inner and outer surface of the duct and across the downstream wake emphasizing the effect of tip gap on the thrust force produced. In addition, their study showed the effect of leading edge radius of the duct on the stall performance and stability of the vehicle. Fleming, Jones and Lusardi ${ }^{3}$ et. al. conducted wind tunnel experiments and computational studies around a 12-inch diameter ducted fan. They concentrated on the performance of ducted fan V/STOL vehicles in crosswind.

Moreover, the ducted fan design and performance analysis were widely performed by using computational flow modeling. Lind, Nathman and Gilchrist ${ }^{4}$ carried out a computational study using a panel method. They compared their results to the experimental results from Martin and Tung ${ }^{2}$. Graf, Fleming and Wings ${ }^{5}$ improved ducted fan forward flight performance with a recently designed leading edge geometry which was a significant factor in offsetting the effects of the adverse aerodynamic characteristics. He and Xin ${ }^{6}$ developed the ducted fan models based on a non-uniform and unsteady ring vortex formulation for duct and blade element model for fan. Numerical study in both flight conditions, axial flight and cross wind condition flight were conducted and validated with measured data. Cheng and Rajagopalan ${ }^{7}$ developed an accurate grid generation methodology known as "the curve adaptive option" to model several industrial ducted fans. An axisymmetric, incompressible Navier-Stokes solver was applied to calculate the flow field of a duct fan. The computational results agreed well with available wind tunnel test data. Ahn and Lee ${ }^{8}$ applied a computational method to their ducted fan system to identify the design parameters which affect its performance. Their ducted fan system was designed by using the stream-surface based axisymmetric analysis which provided the physical characteristics and design parameters of the system. Lind, Ko, Ohanian and Gelhausen ${ }^{9}$ developed a computer code aiming the preliminary design of a ducted fan system. This code was validated using data from many wind tunnel and flight tests. Further, it was extensively used in the design of commercial ducted fans. Recently, Zhao and Bil ${ }^{10}$ proposed a CFD simulation to design and analyze an aerodynamic model of a ducted fan UAV in preliminary design phase with different speeds and angles of attack. 
The current study uses experimental and computational analysis around a ducted fan that has a 5 " diameter. By these analyses, complicated flow field around the ducted fan in hover and horizontal flight conditions is investigated. Flow features such us inlet lip separation, distortion of inlet flow features before and after the axial fan rotor, influence of rotor tip speed, influence of horizontal flight velocity and the interaction of the cross wind with fan exit jet are investigated through experiments and computations. For high-resolution mean flow experiments, a particle image velocimeter (PIV) is used. Axial and radial velocity components at the inlet/exit region of the ducted fan are measured in hover and horizontal flight. By measuring axial and radial velocity components, the effect of leading edge duct lip separation on the flow field into the fan rotor is analyzed.

For the computational investigations, three-dimensional incompressible Reynolds Averaged Navier-Stokes (RANS) equations are solved using a commercial solver, FLUENT. In order to accelerate the viscous flow computations, a rotor disk model based on radial equilibrium equation, energy equation and the conservation of angular momentum principle is integrated into the viscous flow solver. The specific actuator disk based fan-model uses a prescribed static pressure rise across the rotor disk for a time efficient simulation of the fan rotor. The paper describes a method to compute the static pressure rise at each radial position of the rotor blade in function of the rotor exit absolute velocity.

The eventual goal of the current investigation is to compute the axial fan rotor in the rotor frame of reference using the actual 3D geometry of the rotor blades using a sliding mesh approach. This approach will allow an accurate representation of the tip leakage flow driven vortices, secondary flows, endwall boundary layers and the interaction of inlet flow distortion with the fan rotor tip region flow. It is also possible to prescribe various casing and rotor tip treatments using the existing experimental results and computational studies. With proper casing/tip treatments applied to a well designed fan rotor may improve the actual thrust of the fan, the energy efficiency and eventually the range of the vehicle. The reduction of the momentum deficit in tip vortices and the elimination of some of tip vortex and rotor downstream region interactions may result in the improvements of the aero-acoustic signature of the fan rotor. The reduction in the strength of tip vortices may also reduce the mechanical vibrations of the V/STOL UAV system under consideration for improved reliability and operability.

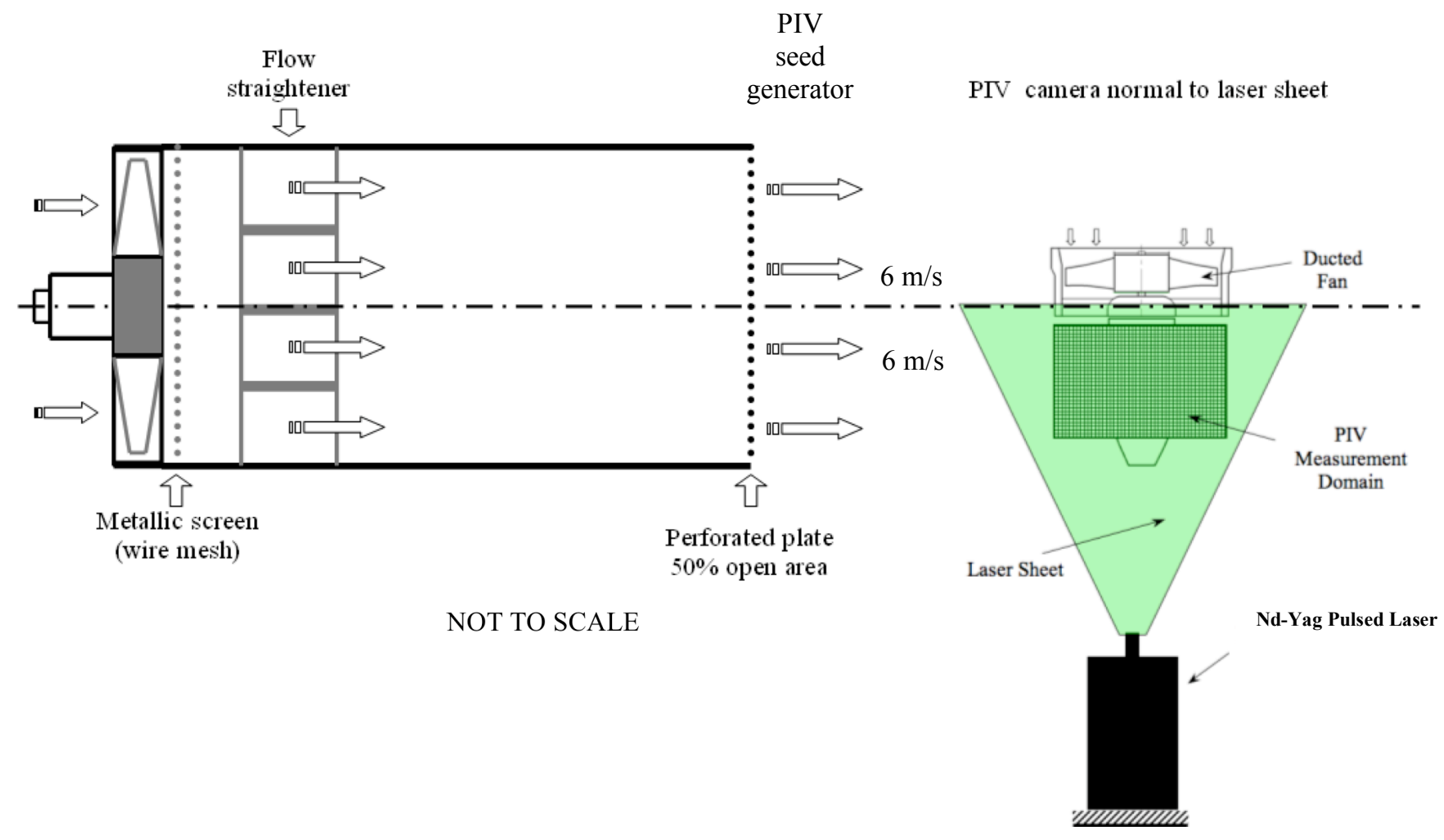

Figure 2. Cross wind blower, the ducted fan and the PIV system orientation 


\section{Experimental Setup}

Cross Wind Blower: A test rig is designed to investigate the local flow features in and around a 5 inch diameter ducted fan using a planar PIV system. The set-up has also provisions for seeding the fan flow field with a smoke generator based on a fluidized based system using fog fluid. Figure 2 shows a sketch of the crosswind blower that can generate about $6 \mathrm{~m} / \mathrm{s}$ uniform mean flow just upstream of the ducted fan unit. The axial flow fan driving the cross wind blower is capable of generating $5.58 \mathrm{~m}^{3} / \mathrm{s}(10,594 \mathrm{cfm})$. There is a wire mesh screen at just downstream of the axial flow fan. The flow passes through a 10 inch wide flow straightener section. Finally, there is a perforated plate (50\% open area) at the exit of the crosswind blower. The grill, flow straightener and the perforated plate at the exit provide a uniform mean flow at the exit of the system. The uniformity of the blower exit mean flow $(6 \mathrm{~m} / \mathrm{s})$ is determined by a hot wire anemometer. The turbulence intensity of the uniform flow is less than $1 \%$ based on the rms fluctuation velocity fluctuations normalized by the mean flow magnitude. An AC inverter connected to the AC motor of the axial fan unit can adjust the mean flow velocity magnitude.

Ducted Fan Model: The brushless DC electric motor driving the five bladed ducted fan rotor is speed controlled by an electronic speed control (ESC) system. The high efficiency electric motor driving the fan can deliver $1.5 \mathrm{~kW}$ power $(2.14 \mathrm{HP})$. The phase-locked PIV measurements are triggered by using an optical once-per-revolution device located near the hub of the rotor exit. An infrared beam is reflected from a highly reflective surface attached to the rotor hub. This once-per-rev pulse provides a phase-locked triggering of the PIV data collection system. The relative position of the rotor can be adjusted accurately in relative to the position of the laser light sheet that contains the rectangular PIV measurement domain located at the upstream and downstream of the rotor as shown in Figure 2. Figure 3 shows the five bladed ducted fan that is used in the present PIV experiments. The geometric specifications are presented in Table 1 This ducted fan unit is designed for small scale uninhabited aircraft. This unit is

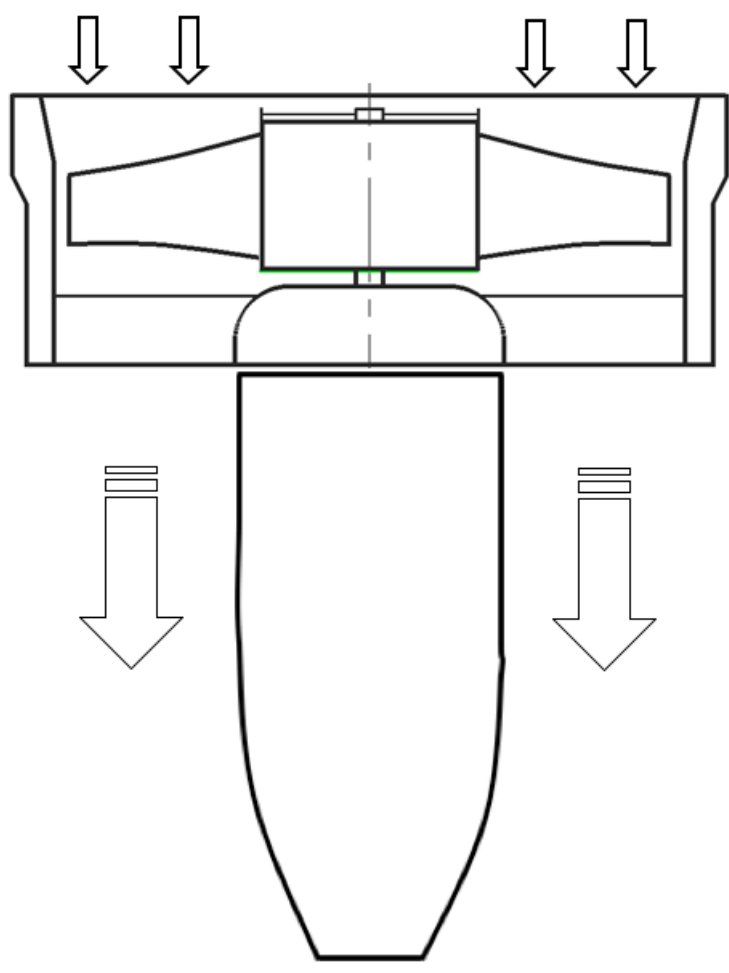

Figure 3. 5 inch diameter ducted fan

\begin{tabular}{|l|c|}
\hline Rotor hub diameter & $52 \mathrm{~mm}$ \\
\hline Rotor tip diameter & 120 \\
\hline Duct inner diameter & 126 \\
\hline Blade height h & 34 \\
\hline Tip clearance t/h & $8.7 \%$ \\
\hline Max. blade thickness @ tip & 1.5 \\
\hline Tailcone diameter & 52 \\
\hline Tailcone length & 105 \\
\hline
\end{tabular}

\begin{tabular}{|c|c|c|c|}
\hline & HUB & $\begin{array}{c}\text { MID } \\
\text { SPAN }\end{array}$ & TIP \\
\hline Blade inlet angle $\beta_{1}$ & $60^{\circ}$ & $40^{\circ}$ & $30^{\circ}$ \\
\hline Blade exit angle $\beta_{2}$ & $30^{\circ}$ & $45^{\circ}$ & $60^{\circ}$ \\
\hline Blade chord $\mathrm{mm}$ & 32 & 30 & 28 \\
\hline \multicolumn{3}{|c|}{13000} \\
\hline Design rpm N & \multicolumn{2}{|c|}{} \\
\hline Tip Mach number & $\Omega \cdot r_{\text {tip }} / \sqrt{\gamma R T_{\infty}}$ & 0.28 \\
\hline $\begin{array}{c}\text { Reynolds number } \\
\text { (mid-span) }\end{array}$ & $\rho W_{m} c / \mu$ & $7 \times 10^{4}$ \\
\hline
\end{tabular}

Table 1. Geometric specifications of ducted fan 4

American Institute of Aeronautics and Astronautics 
manufactured from carbon composite material and has six vanes at the exit of the fan in order to remove some of the swirl existing at the exit of the rotor. A tail cone is used to cover the motor surface and hide the electrical wiring. The system is mounted by using two straight structural struts.

\section{PIV Measurement Technique}

The PIV technique ${ }^{11-15}$ measures instantaneous velocity components of a flow field over a determined area. Small particles existing in a fog generated by a fluidized bed system are introduced into the fluid flow, and the region of interest is illuminated by a light sheet provided by short Nd-Yag laser pulses lasting as short as a few nanoseconds. The subsequent step is the recording of the displacement of particles via one or two CCD cameras depending on the specific PIV technique used. As a summary, four basic steps should be mentioned in an experimental procedure:

1. Flow is seeded.

2. The flow region of interest is illuminated.

3. Scattering light from the particles forming the speckle images is recorded by cameras.

4. Recordings are analyzed by means of a correlation based software system.

The scattered light from seeding particles is recorded by a camera. The initial position of a particle is recorded on the first frame of the camera right after the first laser pulse fires. In general, a typical duration of a laser pulse is about 30 nano seconds in a flow field similar to the current study. Its final position is recorded in the same way on the second frame of the same camera when the second laser pulse fires. The time interval between the two frames is usually determined by the mean flow speed in the area of investigation. The order of magnitude of this time separation between the two frames is "micro seconds". Since the displacement of the particle and the time interval between the two subsequent laser pulses are known, the velocity of the particle can be calculated by the simple equation: speed=distance/time. A comprehensive explanation of this technique is given by R.J. Adrian ${ }^{12}$.

In this current study, the inlet and exit flow performance of a 5 inch diameter ducted fan was quantified by using the PIV technique. Axial and radial components of velocity profiles were measured near the inlet and exit planes of the ducted fan. Two separate measurement domains of [156 $\mathrm{mm} \times 96 \mathrm{~mm}$ ] are used in inlet and exit flow. Figure 2 illustrates the PIV setup in which the fan exit field is measured. For the measurement of inlet flow velocities, the ducted fan is flipped vertically. The PIV measurement domains are illuminated by a double cavity

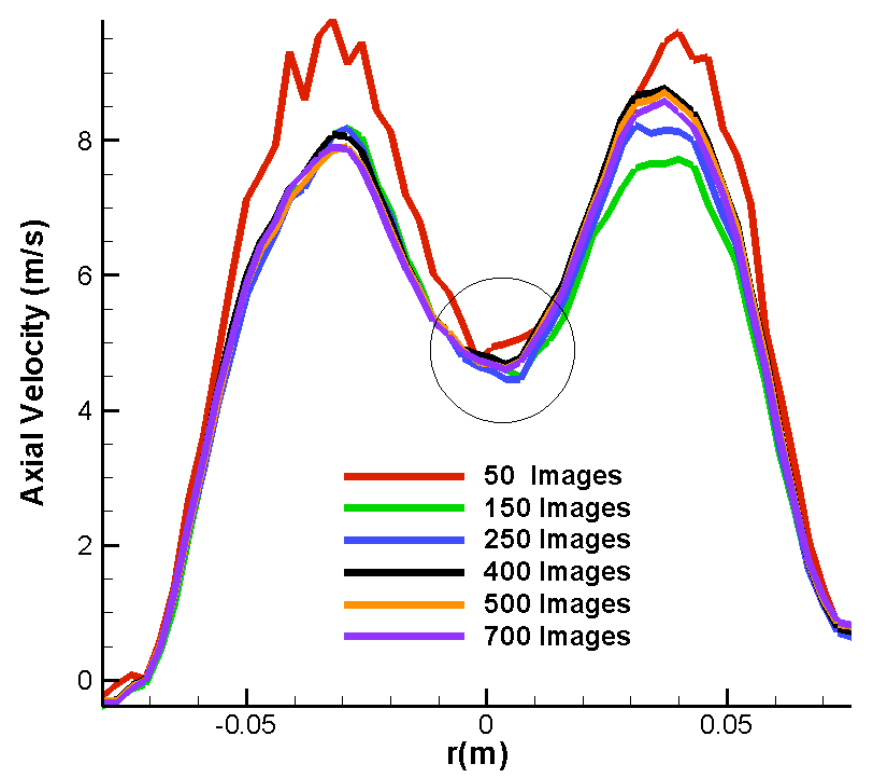

Figure 4. Influence of ensemble averaging "image sample size" on the axial velocity component 5

American Institute of Aeronautics and Astronautics 
frequency doubled pulsating Nd-Yag laser which has an emitted radiation wavelength of $532 \mathrm{~nm}$ (green) and $120 \mathrm{~mJ}$ pulse energy level. Pairs of images from measurement domains are captured by an 80C60 HiSense PIV/PLIF camera. CCD camera is positioned normal to the laser sheet.

In planar PIV measurements, two components of the velocity vector are measured in the plane illuminated by a laser sheet. The current study focuses on measuring the axial and radial components of the local velocity vectors. These measurements are based on the image maps obtained by the CCD camera. The CCD camera should be aligned normally to the laser sheet. When the camera and the laser sheet are aligned, the flow field is seeded. The image pairs of PIV domains are recorded. The image maps are divided into $32 \times 32$ pixel interrogation areas and $25 \%$ overlapping is used. All 700 image pairs are adaptive correlated, moving average validated and then ensemble averaged to obtain true mean flow. The ensemble size is of critical importance in achieving statistically stable mean velocity distributions in any PIV data reduction process. Figure 4 presents the influence of ensemble averaging sample size on the spanwise distribution of the most significant velocity component. Figure 4 indicates that an ensemble size of 400 is optimal in achieving a statistically stable average in the current set of experiments.

\section{Computational Technique}

RANS simulation and computational domain: A simulation of the mean flow field around the ducted fan was performed using a commercial code Ansys/Fluent. The specific computational system solves the Reynolds Averaged Navier-Stokes equations using a finite volume method. The transport equations describing the flow field are solved in a given domain that is discretized by using an unstructured computational mesh. For the analysis of the flow field around ducted fan rotors, there are many computational modeling options in general purpose fluid dynamics solvers. The most complex and time consuming computational model is the modeling of unsteady/viscous/turbulent flow in and around the fan rotor by using an exact 3D model of rotor geometry using a sliding mesh technique. This type of solution is usually lengthy and requires significant computer resources especially in the forward flight mode when an axisymmetric flow assumption is not true. The current RANS computations use a simplified rotor model termed as "Actuator disk model" for the generation of the general inviscid flow features of the fan rotor. A k- $\varepsilon$ turbulence model was invoked for the current computations.

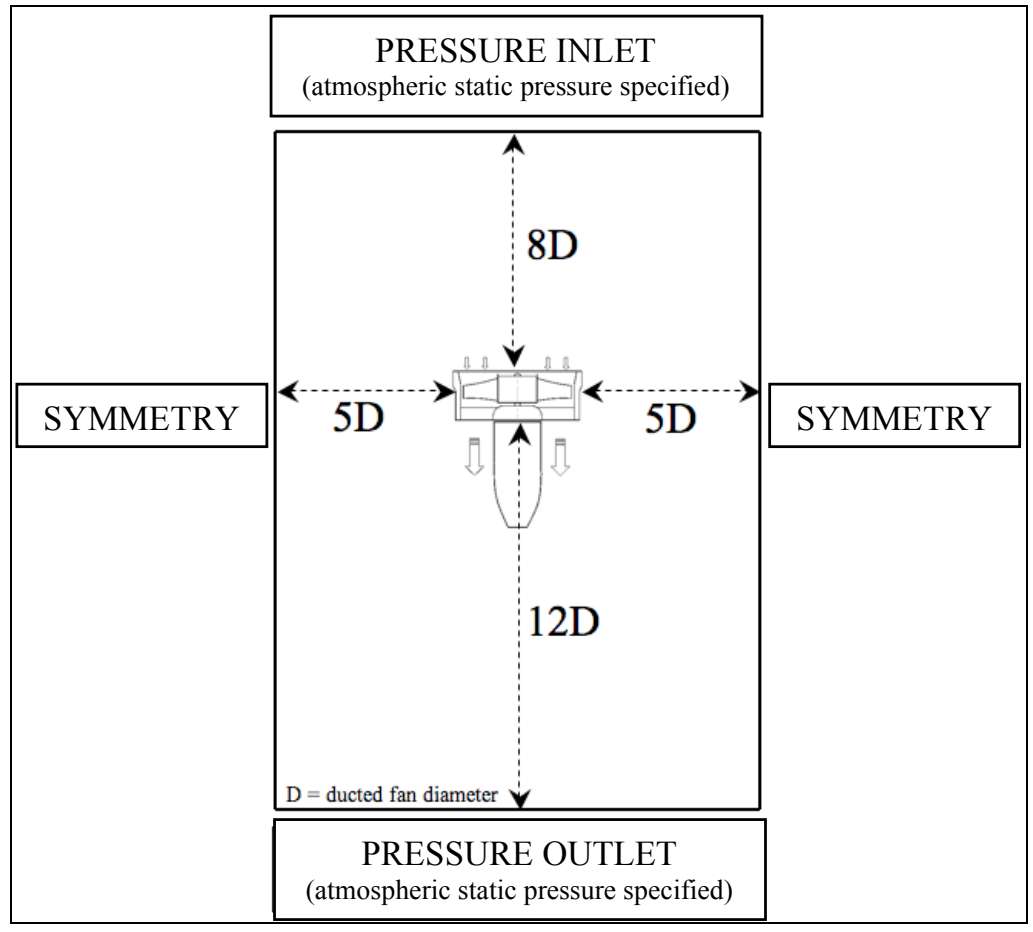

Figure 5. The computational domain and the boundary conditions for RANS simulations (drawing not to scale) 6

American Institute of Aeronautics and Astronautics 
Boundary conditions: Three dimensional and incompressible Navier-Stokes equations are solved in the computational domain since the tip Mach number of the current fan is about $M=0.28$. Figure 5 shows the specific boundary conditions implemented in the solver. The duct and tail-cone surfaces are considered as solid walls with no-slip condition. On the side surfaces, symmetry condition is assumed. For the hover condition, a pressure inlet boundary is assumed on the top surface. Atmospheric static pressure is prescribed on the top surface. Pressure inlet boundary is treated as loss-free transition from stagnation to inlet conditions. The solver calculates the static pressure and velocity at the inlet. Mass flux through boundary varies depending on interior solution and specified flow direction. Pressure outlet boundary condition is assumed on the bottom surface for hovering condition. Pressure outlet boundary interpreted as atmospheric static pressure of environment into which the flow exhausts. An additional "Fan" type condition was set using an "actuator disc model" replacing the ducted fan rotor.

Actuator disk model: A simplification of flow modeling across the rotor is implemented in this study. The complex 3D rotor flow field in the rotating frame of reference is replaced by a simplified "actuator disk model" originating from the simultaneous use of the radial equilibrium equation, energy equation and the conservation of angular momentum principle across the fan rotor. The radial equilibrium equation is the force balance in radial direction at a given axial position, balancing the pressure forces in radial direction with the centrifugal force. The viscous effects are ignored in this simplified and easy to implement "actuator disk model".

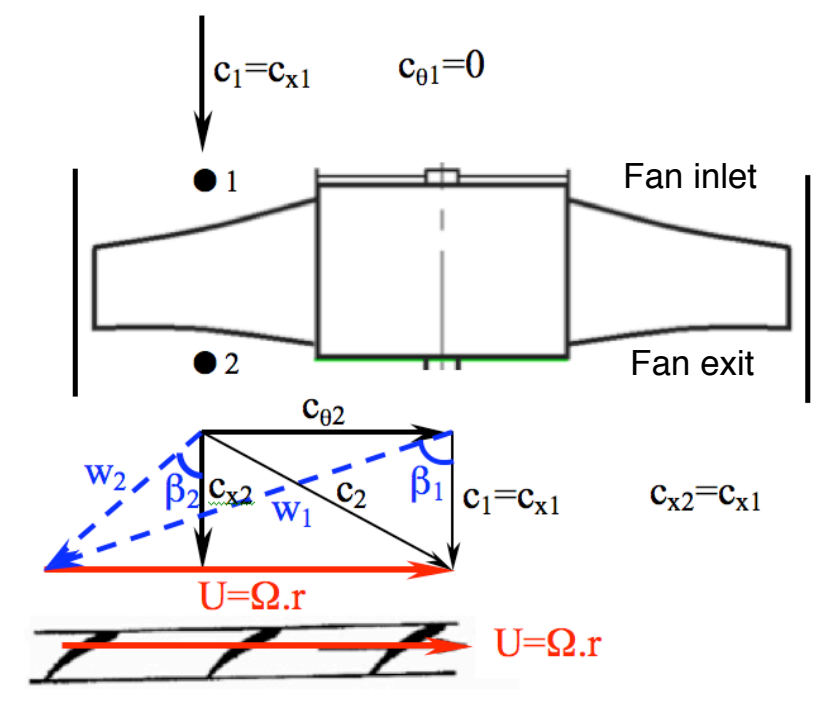

Figure 6. Velocity triangles at the inlet and exit of the ducted fan rotor

In summary, a pressure change term is computed at each radial position of the rotor from hub to tip. The magnitude of the static pressure jump term across the rotor is closely related to the amount of stagnation enthalpy change from the rotor inlet to exit. The stagnation enthalpy increase from the rotor inlet to exit is the same as the rate of energy provided to the fluid by the rotor per unit mass flow rate of the duct flow. The conservation of angular momentum principle and energy equation suggests that the magnitude of this jump is mainly controlled by the tangential (swirl) component of the flow velocity $c_{\theta 2}$ in the absolute frame of reference at the exit of the rotor and rotor angular velocity.

Velocity triangles: Figure 6 presents the velocity triangles of the ducted fan rotor at inlet (1) and exit (2). $\beta_{1}$ and $\beta_{2}$ are the blade inlet and exit angles measured from the axial direction. Since the tip Mach number $(0.28)$ of the rotor is not in the compressible flow range, it is reasonable to assume that the internal energy at the rotor inlet $e_{1}$ and exit $e_{2}$ is the same, $e_{1}=e_{2}$. In a ducted fan rotor, it is realistic to assume that the "axial component" of the absolute velocity vector is also conserved from inlet to exit $c_{x 2}=c_{x 1}$. The flow is assumed to be axial at rotor inlet where $c_{1}=c_{x l}$ and $c_{\theta l}=0$. The relative velocity vector at the exit of the rotor $w_{2}$ is smaller than the relative velocity $w_{1}$ at the rotor inlet. While the relative flow $w_{2}$ is diffusing in the relative frame of reference, the absolute flow velocity vector $c_{2}$ is accelerated at the rotor exit, because of added energy to the flow by the rotor. 
Pressure jump across the rotor: Equation (1) represents the change of stagnation enthalpy in the ducted fan rotor system. The right hand side of this equation is the rate of work per unit mass flow rate of air passing from the rotor. The right hand side is also the same as the product of the rotor torque and angular speed of the fan rotor.

$$
\begin{aligned}
& \left(h_{o 2}-h_{o 1}\right)=U\left(c_{\theta 2}-c_{\theta 1}\right) \quad \text { where } \mathrm{U}=\Omega \mathrm{r} \text { and } \quad c_{\theta 1}=0 \\
& {\left[\left(h_{2}+c_{2}^{2} / 2\right)-\left(h_{1}+c_{1}^{2} / 2\right)\right]=U c_{\theta 2}} \\
& {\left[\left(e_{2}+\frac{p_{2}}{\rho_{2}}+c_{2}^{2} / 2\right)-\left(e_{1}+\frac{p_{1}}{\rho_{1}}+c_{1}^{2} / 2\right)\right]=U c_{\theta 2}}
\end{aligned}
$$

Equation (1) is a simplified form of the energy equation from rotor inlet to exit of a ducted fan unit. When $e_{1}=e_{2}$ is substituted into equation (3) because of incompressibility condition, the "Euler equation" or "pump equation" results in as equation (4). Using equations (4) and (5), an equation for the calculation of static pressure jump between the rotor inlet and exit can be obtained.

Calculating the rotor exit swirl velocity $c_{\theta 2}$ : The determination of $c_{\theta 2}$ is performed by using the velocity triangles in Figure (6). Since the blade inlet/exit angle distribution for $\beta_{1}$ and $\beta_{2}$ in radial direction is known from the existing rotor geometrical properties, shown in Table 1. $w_{2}$ is calculated from the assumption that $c_{x 2}=c_{x 1}=c_{1}$. The absolute rotor exit velocity $c_{2}$ is determined by adding $U=\Omega . r$ to $w_{2}$ in a vectorial sense .

$$
\begin{aligned}
& \frac{1}{\rho}\left(P_{o 2}-P_{o 1}\right)=U c_{\theta 2} \\
& \frac{1}{\rho}\left[\left(p_{2}+\rho \frac{c_{2}^{2}}{2}\right)-\left(p_{1}+\rho \frac{c_{1}^{2}}{2}\right)\right]=U c_{\theta 2} \\
& \Delta p=p_{2}-p_{1}=\rho\left[U c_{\theta 2}-\frac{1}{2}\left(c_{2}^{2}-c_{1}^{2}\right)\right]
\end{aligned}
$$

Equation (6) allows enforcing a prescribed pressure jump $\Delta p$ in function of density, radial position, rotor angular speed $\Omega$, rotor exit swirl velocity $c_{\theta 2}, c_{1}$ and $c_{2}$. The amount of rate of energy (per unit mass flow rate) added to the flow by the rotor is specified by the product $U \cdot c_{\theta 2}$ as shown in equations (4) and (5). Equation (6) could be evaluated at each radial position between the rotor hub and tip resulting in the radial distribution of the static pressure jump required by the general purpose viscous flow solver for a "Fan" type boundary condition. $\Delta p$ can be effectively specified in a user defined function "UDF" in the solver. The "Fan" type boundary condition is an effective and time efficient method of implementing a rotor flow field via an "actuator disk model" in a 3D viscous flow computation.

\section{Experimental PIV results and discussion}

In the current study, the aerodynamic performance of the 5 inch diameter ducted fan was quantified by measuring axial and radial velocity components using a PIV technique. Axial and radial velocity components were simultaneously measured on $156 \mathrm{~mm} \times 96 \mathrm{~mm}$ rectangular planes located at $2 \mathrm{~mm}$ away from the duct inlet and exit surfaces. The orientation of the PIV measurement plane is shown in Figure 2. Experiments were performed at two different rotational speeds at 9000 and $15000 \mathrm{rpm}$. The performance of ducted fan was analyzed in hover and forward flight conditions. Forward flight is simulated with a crosswind of $6 \mathrm{~m} / \mathrm{s}$ velocity produced by crosswind blower described in Figure 2. 


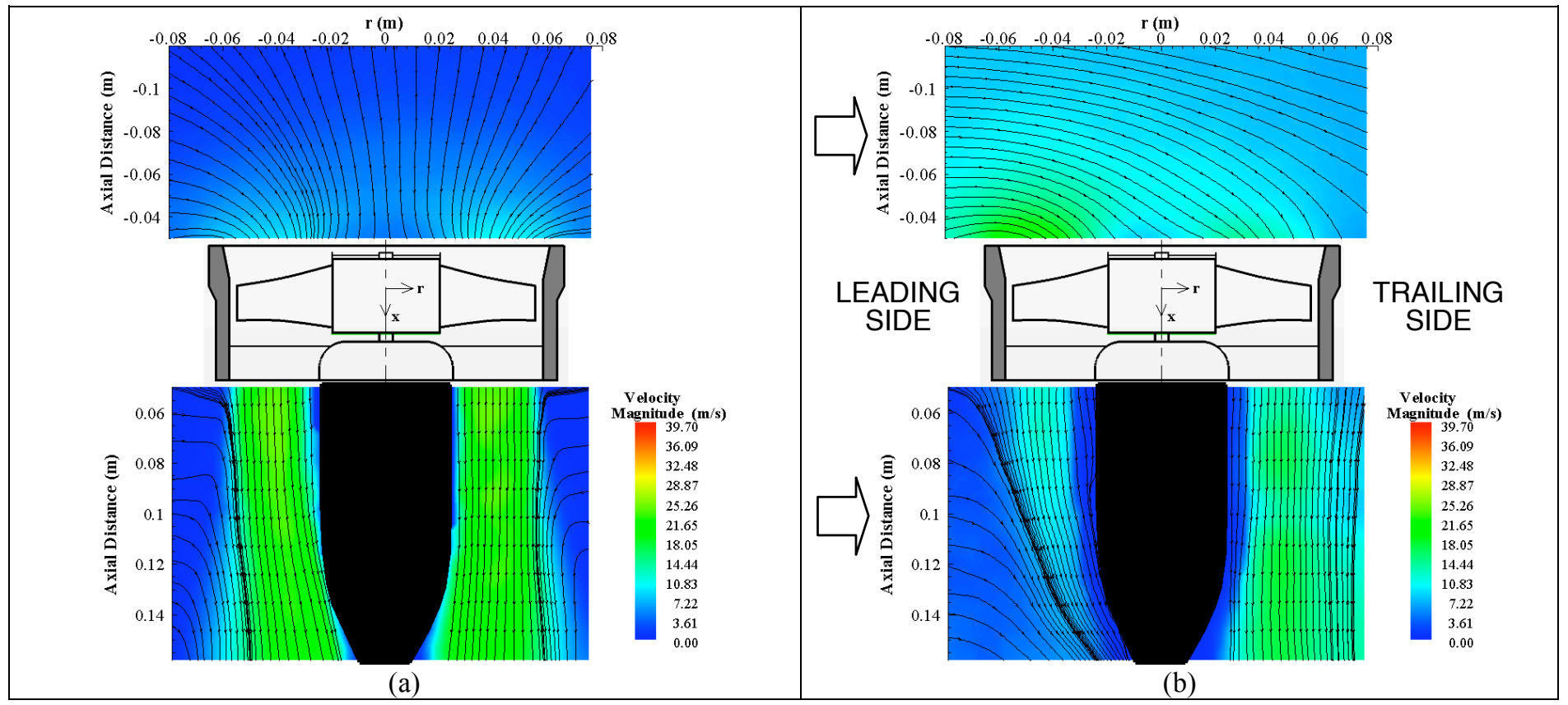

Figure 7. Streamlines at inlet and exit of ducted fan for HOVER (a) and FORWARD FLIGHT (b) (PIV measurements at 9000 RPM)

Figures 7a and 8a show streamlines obtained from PIV measurements at different rotational speeds (9000 and $15,000 \mathrm{rpm}$ ) in hovering. The figures are contour plotted and colored with the magnitude of measured velocity. As expected, magnitude of velocity is increasing at both inlet and exit regions by increasing rotational speed of the fan rotor. The streamline structure and the local magnitude of the velocity vector show a reasonable axisymmetry in hover mode as shown in Figures $7 \mathrm{a}$ and $8 \mathrm{a}$. The exit jet from the fan unit show a visible flow entrainment from the still air region into the exit jet at both rotational speeds. In addition to the flow entrainment, the exit jet region at $15,000 \mathrm{rpm}$ exhibit slight momentum deficit near $\mathrm{x}=0.1$. This momentum deficit could be explained with the existence of the wakes of the six bladed exit guide vanes in the fan unit. The final form of this distribution is also controlled by theunique rotor position defined by the current phase-locking approach.

Figure $7 \mathrm{~b}$ illustrates the change of inlet/exit flow field by the effect of forward flight velocity at $9000 \mathrm{rpm}$. With the influence of the crosswind at $6 \mathrm{~m} / \mathrm{s}$, the distribution of the velocity magnitude at the inlet is distorted due to the separation from the leading side duct lip. Due to the separation region, breathing area of the fan rotor is reduced. At the leading side of the duct, maximum velocity magnitude is shifted towards to hub with the effect of separation. Figure 13 clearly supports the observation that the "leading side" peak in axial velocity at the inlet plane is shifted towards the rotor hub due to inlet lip separation. However, the trailing side peak in inlet plane is shifted towards the blade tip. When the peak is more shifted towards the rotor tip section the work addition to fan exit flow is more significant as shown in Figure 13. Due to more distorted inflow at the leading side, exit flow average velocity magnitude is slightly decreased at the leading side. The streamlines near the trailing side at the inlet plane are more normal to the fan inlet plane indicating slightly higher mass flow rate on this side than the leading side. The trailing side of the duct is affected less from the crosswind. Streamlines at the exit flow clearly show the influence of forward flight velocity on the high momentum jet exit fluid. With the effect of the crosswind, the exit jet is deflected and pushed towards to the tip of the tail cone surface at the leading side. Trailing side is affected less than leading side as expected.

Axial velocity plot shown in Figure 13 is drawn along a horizontal line $3 \mathrm{~mm}$ away from the exit and inlet surfaces to demonstrate the effect of crosswind velocity on the axial velocity component. Introduction of crosswind 


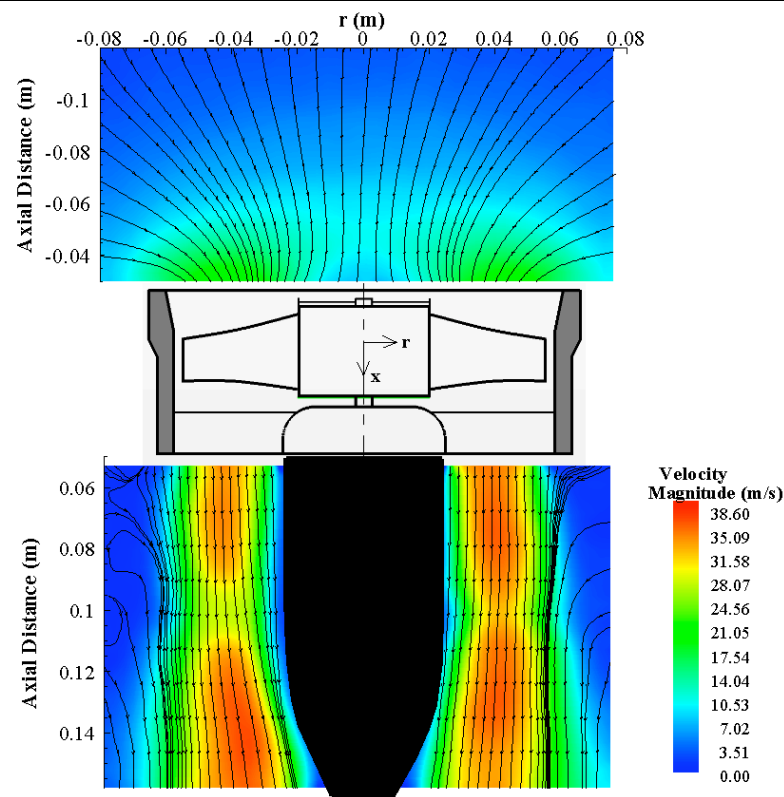

(a)

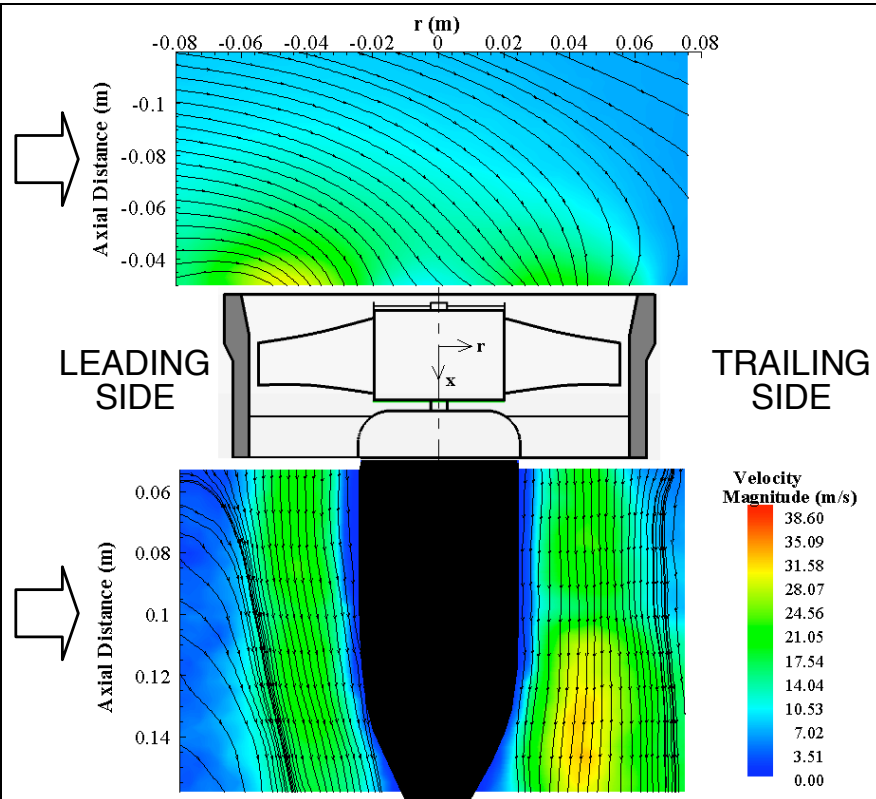

(b)

Figure 8. Streamlines at inlet and exit of ducted fan for HOVER (a) and FORWARD FLIGHT (b) (PIV measurements at 15000 RPM)

HOVER

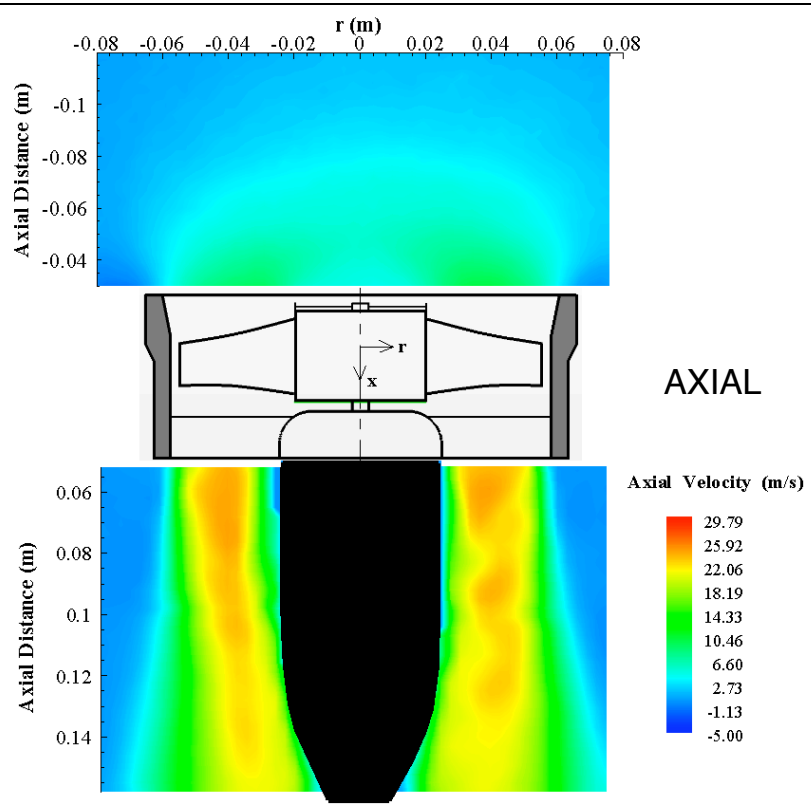

(a)
HOVER

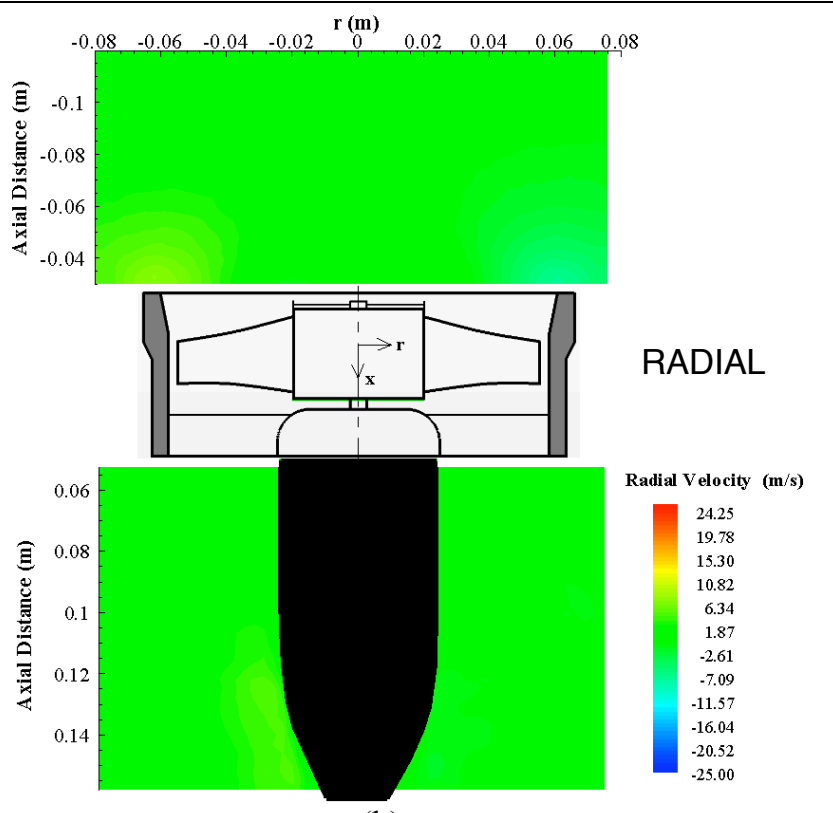

(b)

Figure 9. Axial (a) and Radial (b) velocity components at HOVER condition (PIV measurements at 9000 RPM) 
to simulate the forward flight results in a reduced axial velocity near the leading edge duct lip. That can be explained by occurrence of a separation bubble on the leading side lip inside the duct. Figure 13 also indicates that the axial velocity near the trailing side lip is relatively enhanced when compared to the hover condition.

Figure $8 \mathrm{~b}$ shows the effects of forward velocity at $15000 \mathrm{Rpm}$. An increase in the rotational speed at forward flight, effectively energizes the air flow at the inlet. The effect of separation at the leading edge is reduced by increasing rotational speed of the fan. The streamlines near the inlet are more normal to the inlet surface at 15000 rpm. The streamlines in the exit jet area are much less influenced by the mainstream flow. Figure 8.a shows that the mass flow rate passing from the ducted fan at $15000 \mathrm{rpm}$ is much higher than the case for $9000 \mathrm{rpm}$. The axial velocity peak in exit plane is almost doubled when the rotational speed is increased to $15000 \mathrm{rpm}$.

Figures 9 and 10 illustrates the axial and radial velocity components at 9000 and $15000 \mathrm{rpm}$ for hover condition. Increase in axial velocity by rotational speed increase, results in a significant enhancement of axial momentum of the system. The radial velocities that are usually in much smaller magnitudes than the axial components show a symmetrical distribution with respect to the axis of rotation. The axial and radial velocity components in hover condition results in a reasonably uniform distribution of side forces around the duct.

Introducing crosswind velocity to the field changes the distribution of radial flow velocity around the duct. Figures 11.b and 12.b indicates an abrupt increase near the leading side of the duct lip. That increase in radial velocity is the result of the strong re-circulatory flow near the leading side as expected. The flow non-uniformities near the leading side of the lip and the strong variations between the leading and the trailing side of the exit jet result in strong pitch-up moment acting on the ducted fan. It can be observed that by the increase of rotational speed radial velocity is also increasing. But the same amount of increase can also be seen on the radial velocity distribution in hovering mode.

As increasing rotational velocity, axial momentum of the flow is increased. That helps the ducted fan fight with the negative effects of crosswind. 


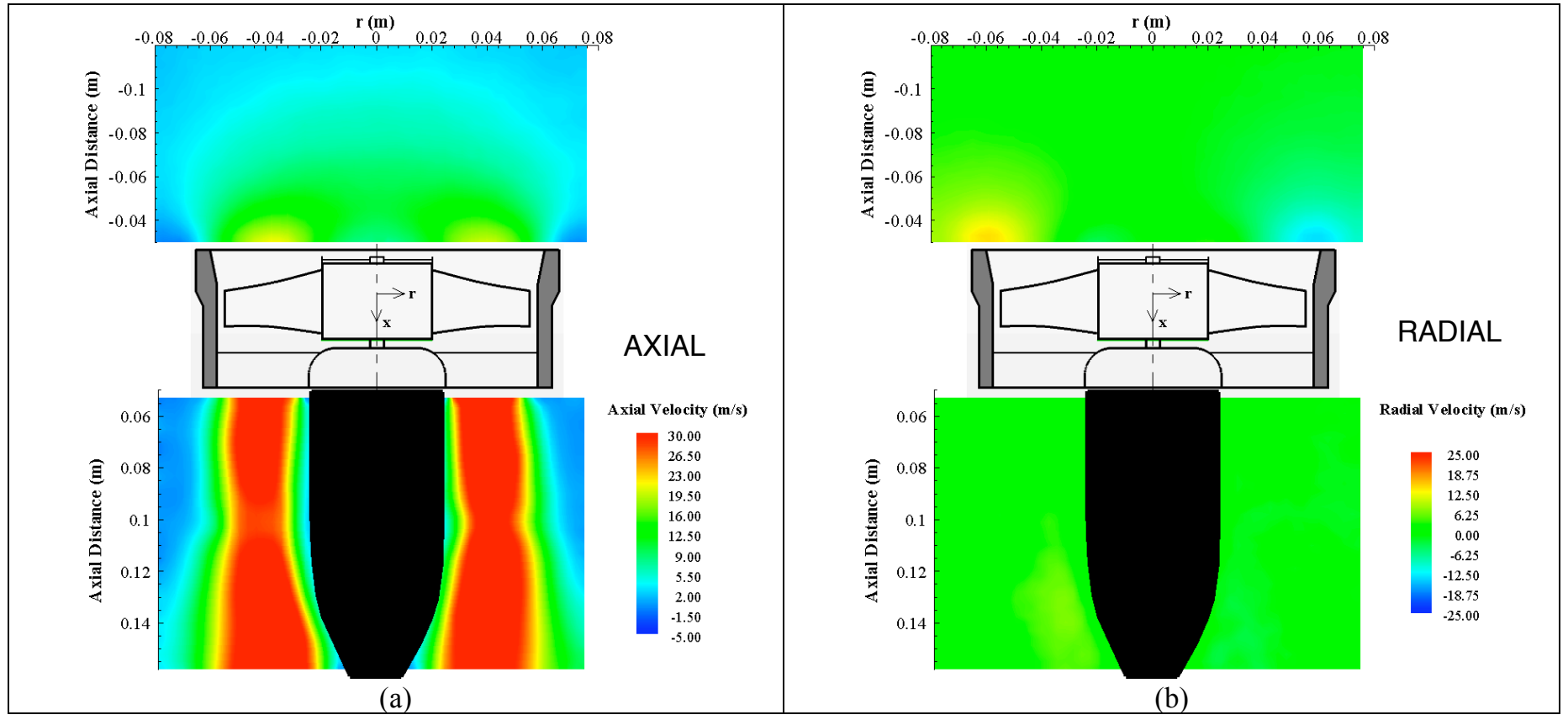

Figure 10. Axial (a) and Radial (b) velocity components at HOVER condition (PIV measurements at 15000 RPM)

FORWARD FLIGHT $6 \mathrm{~m} / \mathrm{s}$

FORWARD FLIGHT $6 \mathrm{~m} / \mathrm{s}$

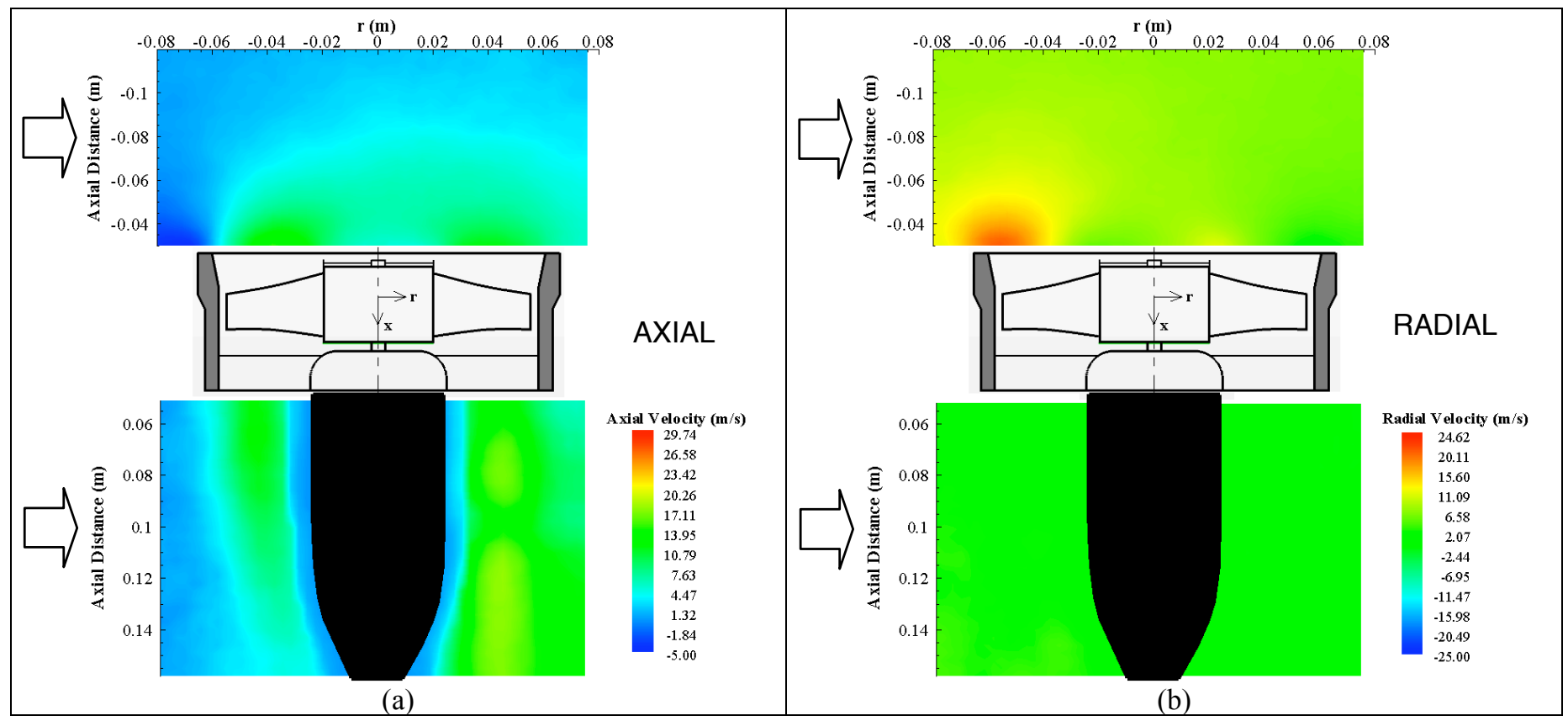

Figure 11. Axial (a) and Radial (b) velocity components at FORWARD FLIGHT condition (PIV measurements at 9000 RPM) 


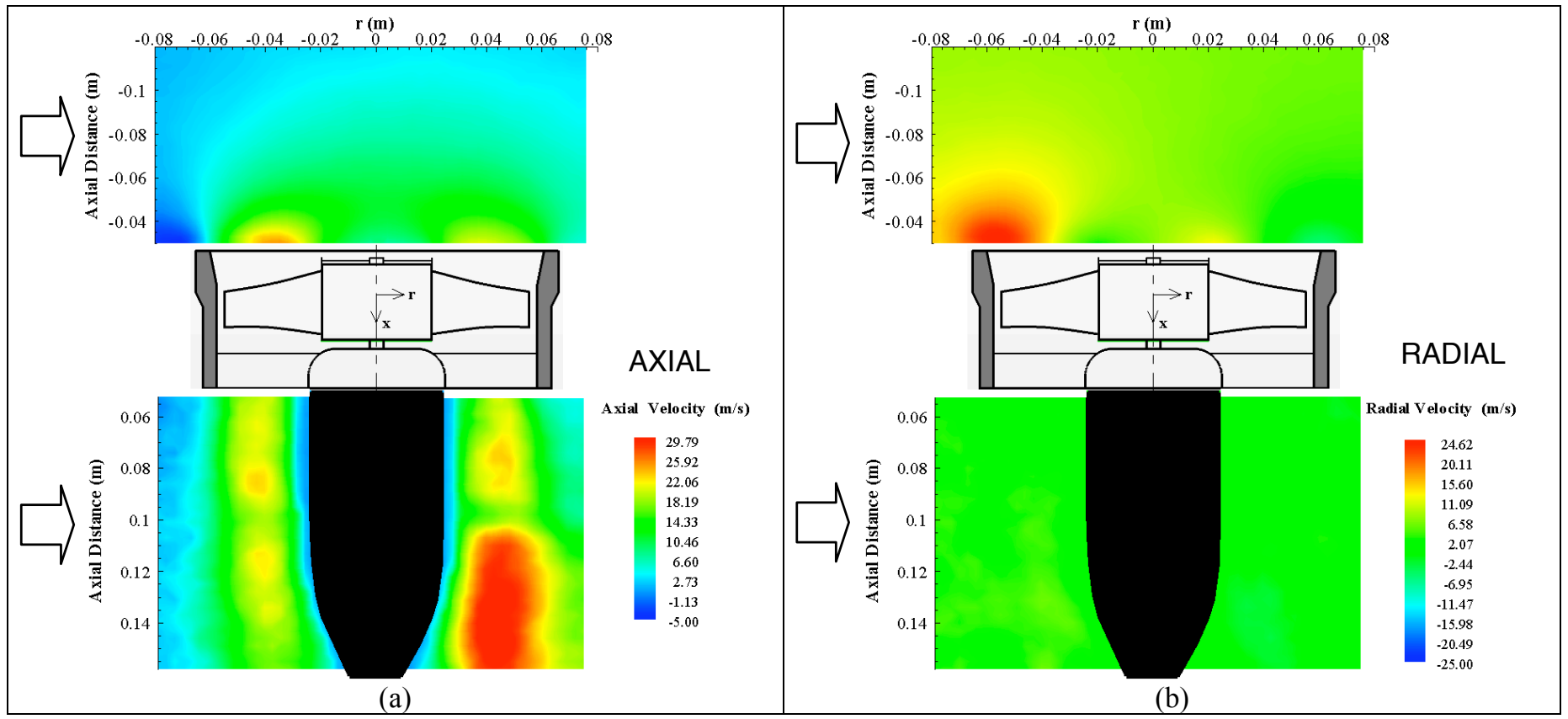

Figure 12. Axial (a) and Radial (b) velocity components at FORWARD FLIGHT condition (PIV measurements at 15000 RPM)

the forward flight scenarios is dropping axial velocity at the inlet near the leading edge duct lip. That can be explained by occurrence of separation bubble on the leading side lip.

Figure 8.b shows the effects of forward velocity at $15000 \mathrm{Rpm}$. An increase in the rotational speed at forward flight, effectively works in energizing the air flow at the inlet. The effect of separation at the leading edge is reduced by increasing rotational speed of the fan from $9000 \mathrm{rpm}$ to $15000 \mathrm{rpm}$. A similar conclusion can also be drawn by analyzing the difference in exit flow streamlines at different rotational speeds.

Figure 9 and 10 illustrates axial and radial velocity components at 9000 and $15000 \mathrm{rpm}$ for hover condition. Increase in axial velocity by the change of rotational speed, results in an increase in axial momentum of the system. Radial velocities are distributed reasonably symmetrically. That results in a symmetric distribution of side forces around the duct.

As mentioned above, introducing a crosswind velocity to the field changes the distribution of radial flow velocity around the duct. Figures 11.b and 12.b indicates an abrupt increase of the radial velocity component near the leading side duct lip. That increase in radial velocity will increase the drag forces at the leading side as expected. That change in drag force will lead to a change in pitching moment. The PIV measurements show that the increase of rotational speed is also increasing the radial velocity magnitude. Axial momentum of the flow is increased when the rotational speed of the fan is increased to $15000 \mathrm{rpm}$ as shown in Figure 12.a. This axial momentum enhancement helps the ducted fan to fight with the negative effects of crosswind. 


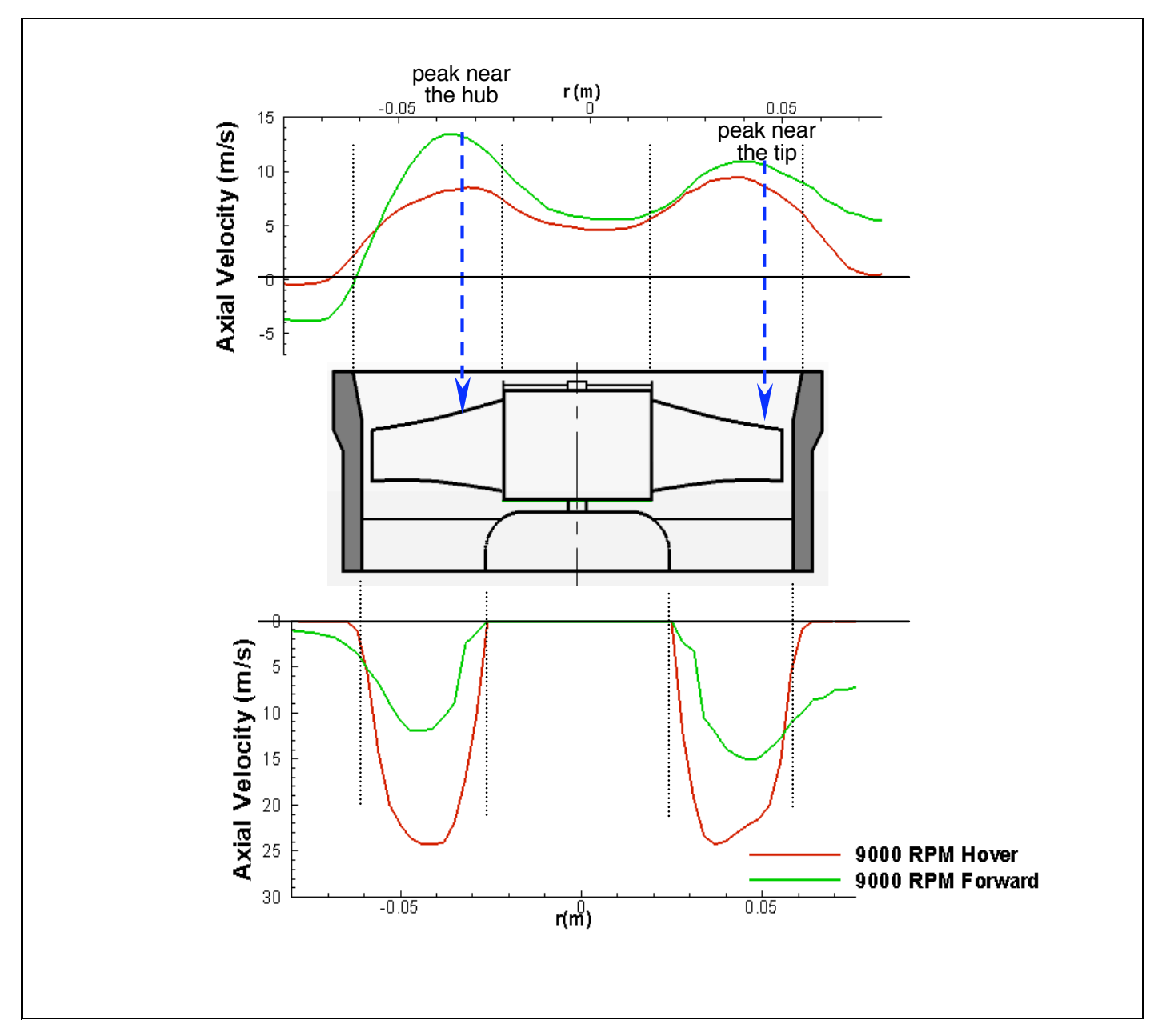

Figure 13. Axial Velocity Distribution at the inlet and exit of ducted fan at 9000 RPM

\section{Computational Predictions in the Ducted Fan}

In the current study, incompressible Reynolds Averaged Navier Stokes equations are solved by using a commercially available code as described in section IV. The results of 3D computations are compared to the PIV experiments. The computed axial velocity component at $3 \mathrm{~mm}$ away from the duct inlet surface is compared to the results of PIV measurements in Figure 14. The computational and experimental results are in good agreement near the leading side of the fan at the inlet plane. The computational predictions near the leading side and the trailing side show a reasonably symmetrical axial velocity distribution.

There is a slight underprediction of the PIV measurements near the trailing side of the duct as shown in Figure 14. In a phase-locked PIV approach, measurements are always performed at the same circumferential position of the rotor blade. Since we used a five bladed fan rotor, the right side of the domain in Figure 14 contains a rotor blade in the laser sheet. However the left side of the domain where $r<0$ does not contain a rotor blade in the laser sheet. The slight underprediction is related to the specific phase-locked position of the rotor during the PIV measurements. Because of the blockage effect introduced by the rotor blade in the laser sheet plane, the PIV measured axial flow velocity magnitude is slightly altered when compared to the computational result. . 


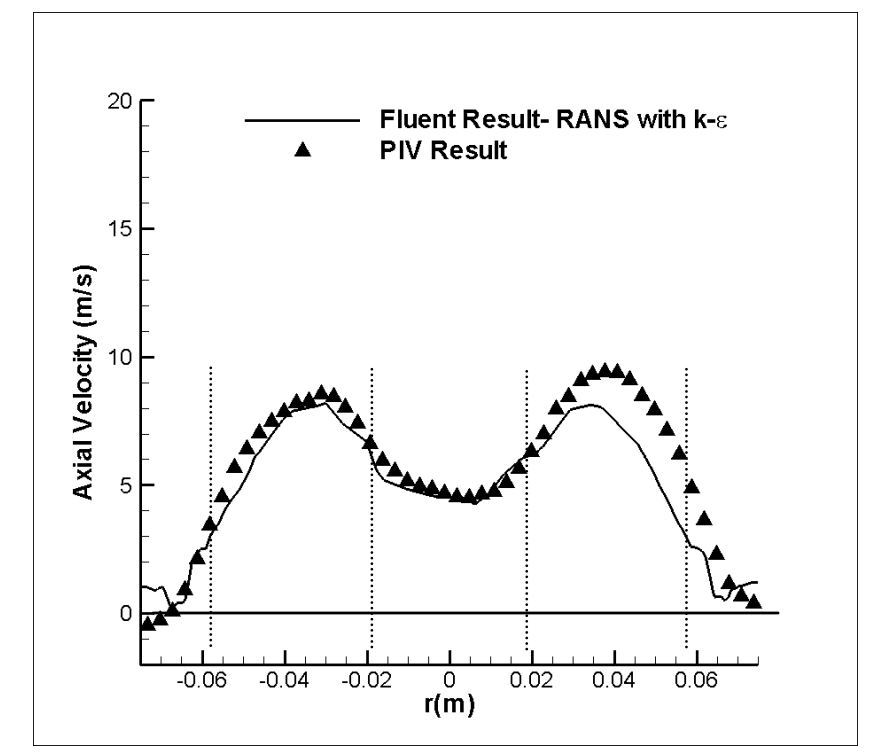

Figure 14. Computed and measured inlet axial velocity comparison at HOVER condition

\section{Conclusions}

In this study, an experimental and computational investigation around 5 inch diameter ducted fan for V/STOL UAV applications was carried out.

The velocity field around the ducted was measured using a planar PIV system. Axial and radial velocity components at the inlet/exit region of the ducted fan were measured in hover and horizontal flight at $6 \mathrm{~m} / \mathrm{s}$.

Beside the experimental study, a computational study based on solving incompressible Navier-Stokes equations was carried out. The specific actuator disk based fan-model uses a prescribed static pressure rise across the rotor disk for a time efficient simulation of the fan rotor.

The results of PIV measurements have proven that the performance of the ducted fan was highly affected from the crosswind velocity. In crosswind, by the effect of the forward flight velocity, a separation region that restricts the effective breathing area of the fan rotor, was always observed at the leading side of the ducted fan. That separation bubble has proven to affect the exit flow of the fan rotor.

By the introduction of inlet distortion at the leading side, flow characteristics of the fan was highly altered compared to the fan design conditions. The inlet flow distortion due to leading side lip separation results in a drop in thrust force generated by the system.

The measured differentials existing between the leading side and trailing side of inlet flow are likely to generate excessive moment imbalance during the forward flight of the ducted fan based V/STOL UAV. The measured local flow differentials at the inlet plane directly translate into non-uniformities in the exit jet of the ducted fan.

The experimental results showed that an increase in the rotational speed of the fan enhances the axial velocity component at the inlet and exit sections in hover condition, as expected. That increase in the rotational 
speed of the fan rotor has proven to improve the performance of the ducted fan in forward flight due to improved axial momentum change in the ducted fan.

An increase in the rotational speed of the fan from $9000 \mathrm{rpm}$ to 15000 reduced the effect of the leading side separation bubble.

The specific actuator disk based fan-model was able to predict the inlet flow axial flow velocity distribution well at $9000 \mathrm{rpm}$ hover condition. A computational study using an unsteady prediction of the ducted fan rotor using the actual 3D fan geometry in the rotating frame of reference is under progress. A sliding-mesh method is under consideration for the computation of the actual rotor flow details in hover and forward flight.

\section{Acknowledgements}

The authors acknowledge the financial support provided by the PSU Vertical Lift Center of Excellence VLRCOE. The technical support provided by the Department of Aerospace Engineering is also acknowledged.

\section{References}

${ }^{1}$ Abrego, A., I. and Bulaga, R., W. , "Performance Study of a Ducted Fan System", AHS Aerodynamics, Aeroacoustic, Test and Evaluation Technical Specialist Meeting, San Francisco, CA, Jan 2002

${ }^{2}$ Martin, P. and Tung, C., "Performance and Flowfield Measurements on a 10-inch Ducted Rotor VTOL UAV", 60th Annual Forum of the American Helicopter Society, Baltimore, MD, June 7-10, 2004.

${ }^{3}$ Fleming J , Jones.T , Lusardi , J. , Gelhausen P.,Enns D., "Improved Control of Ducted Fan VTOL UAVs in Crosswind Turbulence" AHS $4^{\text {th }}$ Decennial Specialist's Conference on Aeromechanics, San Francisco, CA, Jan 21-23, 2004

${ }^{4}$ Lind, R., Nathman, J. , K., and Gilchrist, I., "Ducted Rotor Performance Calculations and Comparisons with Experimental Data" $44^{\text {th }}$ AIAA Aerospace Sciences Meeting and Exhibit, Reno, Nevada, Jan 2006

${ }^{5}$ Graf, W., Fleming, J., Wing, Ng., "Improving Ducted Fan UAV Aerodynamics in Forward Flight" $46^{\text {th }}$ AIAA Aerospace Sciences Meeting and Exhibit, Reno, Nevada, Jan 2008

${ }^{6}$ He, C. and Xin, H., “An unsteady Ducted Fan Model for Rotorcraft Flight Simulation” 62th AHS Forum, Phoenix, Arizona, May 2006

${ }^{7}$ Chang, I.C., and Rajagopalan, R.G., "CFD Analysis for Ducted Fans with validation" $21^{\text {th }}$ AIAA Applied Aerodynamics Conference, Orlando, Florida, June 2003

${ }^{8}$ Ahn, J., Lee, K.T., "Performance Prediction and Design of a Ducted Fan System" $40^{\text {th }}$ AIAA/ASME/SAE/ASEE Joint Propulsion Conference and Exhibit, Fort Lauderale, Florida, July 2004

${ }^{9}$ Ko, A., Ohanian, O.J., Gelhausen, P., "Ducted Fan UAV Modeling and Simulation in Preliminary Design” AIAA Modeling and Simulation Technologies Conference and Exhibit, Hilton Head, South Carolina, August 2007

${ }^{10}$ Zhao, H.W. and Bil, C., "Aerodynamic Design and Analysis of a VTOL Ducted-Fan UAV" $26^{\text {th }}$ AIAA Applied Aerodynamics Conference, Honolulu, Hawaii, August 2008

${ }^{11}$ DANTEC, 2000, “FlowMap Particle Image Velocimetry Instrumentation-Installation \& User's Guide”.

${ }^{12}$ Adrian, R.J., 1991, "Particle Imaging Techniques for Experimental Fluid Mechanics," Ann. Rev. Fluid Mech., Vol. 23, pp. 261-304.

${ }^{13}$ Kahveci, H.S. and Camci C. , 2006, “Flow Around Helicopter Blade Tip Sections Using 2D Particle Image VelocimeterPart I", $11^{\text {th }}$ International Symposium on Transport Phenomena and Dynamics of Rotating Machinery (ISROMAC-11) Honolulu, HI, Paper No: 136 
${ }^{14}$ Kahveci, H.S. and Camci C. , 2006, "Flow Around Helicopter Blade Tip Sections Using A (3D) Stereoscopic Particle Image Velocimeter-Part II ", $11^{\text {th }}$ International Symposium on Transport Phenomena and Dynamics of Rotating Machinery (ISROMAC-11) Honolulu, HI, Paper No: 137

${ }^{15}$ Kahveci, H.S., 2004, "Implementation of a Stereoscopic PIV in Rotating Machinery Including Helicopter Rotor Flows", M.Sc. thesis, The Pennsylvania State University. 